\title{
Occurrence and genetic characterisation of (rossuat Acanthamoeba spp. from environmental and domestic water sources in Queen Elizabeth Protected Area, Uganda
}

Celsus Sente ${ }^{1 *}$, Joseph Erume ${ }^{2}$, Irene Naigaga ${ }^{1}$, Phillip Kimuda Magambo², Sylvester Ochwo ${ }^{2}$, Julius Mulindwa ${ }^{2,4}$, Benigna Gabriella Namara ${ }^{3}$, Charles Drago Kato ${ }^{2}$, George Sebyatika ${ }^{2}$, Kevin Muwonge ${ }^{2}$ and Michael Ocaido ${ }^{1}$

\begin{abstract}
Background: Acanthamoeba is an emerging potentially pathogenic amoeba that has been receiving increasing attention worldwide as a reservoir and potential vector for the transmission of pathogenic bacteria. It is also associated with brain cell damage, keratitis and skin irritation in humans. Its effects are more severe in immunocompromised individuals. This study provides for the first time in Uganda, information on the prevalence and genotypes of Acanthamoeba in environmental and domestic (tap) water.

Methods: A total of 324 environmental and 84 tap water samples were collected between November 2013 and September 2014. The samples were centrifuged, cultured (Non-Nutrient agar seeded with gram-negative bacteria) and observed under a microscope. After confirmation of Acanthamoeba, genomic DNA was extracted for PCR assays by chemical lysis and purification with phenol/chloroform/isoamyl alcohol. Samples that showed the strongest positive bands (400-600 bp) were subjected to cycle sequencing.

Results: Among environmental and tap water samples, 107 (33\%) and 36 (42.9\%) tested positive for Acanthamoeba spp., respectively. Prevalence of Acanthamoeba from specific environmental locations was as follows; Kazinga channel banks (60.7 \%), Fish landing sites (50 \%), River Kyambura (39.6\%) and Kazinga mid channel (5.3\%). There was a significant difference $(p=0.001)$ in the prevalence of Acanthamoeba between sampling sites. The mean (Mean \pm SE) occurrence of the organism was higher in Kazinga channel banks (3.44 \pm 0.49$)$ and Fish landing sites (3.08 \pm 0.53). Correlation between in situ parameters and Acanthamoeba was insignificant except for the Dissolved Oxygen (mg/ML) which was negatively correlated $(r=-0.231, p=0.001)$ to Acanthamoeba. Six distinct partial Acanthamoeba T-genotype groups T1, T2, T4, T5, T6 and T11 were obtained. Ultimately, Acanthamoeba spp., Acanthamoeba hatchetti and Acanthamoeba polyphaga were isolated in the current study.

Conclusions: There was a high prevalence of Acanthamoeba in communal piped tap and environmental water used by communities, indicating poor environmental and domestic water quality.
\end{abstract}

Keywords: Acanthamoeba, Domestic, Environment, Water, Uganda

\footnotetext{
* Correspondence: csente37@gmail.com

${ }^{1}$ Department of Wildlife and Aquatic Animal Resources (WAAR), School of Veterinary Medicine and Animal Resources (SVAR), College of Veterinary Medicine, Animal Resources and Biosecurity (COVAB), Makerere University, P.O. Box 7062, Kampala, Uganda

Full list of author information is available at the end of the article
} 


\section{Background}

Rural communities in and around Queen Elizabeth Protected Area (QEPA) are directly or indirectly dependent on environmental sources of water (fresh water lakes, rivers, streams, water holes, and gravity water) for all their water needs including; drinking, washing, bathing, recreation and agriculture. A significant portion of these communities using environmental or piped tap water sources could be exposed to the risk of contracting waterborne diseases. Waterborne diseases such as cholera, campylobacteriosis, shigellosis, salmonellosis and typhoid among others, are known to affect proportions of rural communities $[1,2]$. Several other waterborne diseases are not often mentioned and yet they might have potential pathogenic effects. Disease effects associated with free-living amoeba (FLA) in humans and animals in Uganda often go undetected because little is known about their presence and distribution in certain environments.

Water and soil-dwelling amoebae are widespread in nature and have been isolated from a variety of engineered water systems, aquatic and terrestrial environments [3-5]. Some FLA of the genera Acanthamoeba, Balamuthia, Naegleria and Hartmannella occasionally invade hosts and cause infections [3, 6]. Acanthamoeba is both opportunistic and pathogenic with two stages in the life-cycle, an active trophozoite that exhibits vegetative growth and a dormant cyst stage with minimal metabolic activity $[3,7]$. Acanthamoeba renders possible intracellular multiplication of Bacillus anthracis, Legionella pneumophila, Vibrio cholerae and Mycobacterium tuberculosis which are responsible for anthrax, legionellosis, cholera and tuberculosis respectively [7-9]. Certain Acanthamoebae spp. are also causative agents of granulomatous amoebic encephalitis (GAE), a fatal disease of the CNS, amoebic keratitis (AK), a painful sight-threatening disease of the eyes $[8,9]$ and have also been associated with cutaneous lesions with sinusitis in HIV/AIDS patients and other immunocompromised individuals $[8,10]$.

Although Acanthamoeba spp. are causative agents of various diseases and carriers of pathogenic bacteria, little is known about their occurrence in Uganda. We, therefore, report for the first time in Uganda the occurrence and genotypic classes of Acanthamoeba.

\section{Methods}

\section{Study area}

The study was conducted in the Queen Elizabeth Protected Area (QEPA) that spans the districts of Rubirizi, Kasese, Rukungiri and Kamwenge in Uganda. The QEPA is a 1,978 sq. $\mathrm{km}$ with coordinates $0012 \mathrm{~S}, 30$ 00E (Latitude: 0.2000; Longitude: $30.00 \mathrm{C00}$ ). The vegetation cover is savannah grassland mixed with forest, woodland and wetland ecosystem. The protected area harbours Lake George and Edward that are joined by a $40 \mathrm{~km}$ long Kazinga channel. Within the protected area are 11 fishing enclaves, with a population of mostly fishermen and pastoral communities.

\section{Ethics}

This study does not require ethical approval.

\section{Sample collection, storage and transportation}

The locations for sample collection were purposively selected based on certain landmarks such as nearness to burial sites/mass graves of hippos that died of anthrax (water sources adjacent to the graves) and nearness to the fishing villages where communities fetch water for domestic use. The water sources included environmental water and communal piped tap water. Environmental water sites were derived as collection points on (1) River Kyambura (R. Kyambura), (2) Kazinga channel bank (KCB), (3) Fish landing site (FLS) and (4) Kazinga mid channel (KMC). The fifth site (communal piped tap water system) is fed by water from the environment (Kazinga channel and River Kyambura) after it is treated.

Important in situ water parameters including; dissolved oxygen $(\mathrm{mg} / \mathrm{l})$, surface water temperature $\left({ }^{\circ} \mathrm{C}\right)$, electrical conductivity $(\mu \mathrm{S} / \mathrm{m}), \mathrm{pH}$, total dissolved solids $(\mathrm{g} / \mathrm{l})$ and oxidation reduction potential $(\mathrm{mV})$ were determined on-site using a Multi-parameter water sensor (Greenspan, USA). Four hundred and eight water samples were collected using $50 \mathrm{ml}$ sterile polypropylene falcon tubes (Discovery Labware, USA). A total number of 408 (324 environmental and 84 tap) water samples were collected. The samples were stored at room temperature and transported to the Makerere University Molecular Biology Laboratory (MOBILA) within $48 \mathrm{~h}$ for culturing and isolation of Acanthamoeba.

\section{Laboratory analysis}

This was done by culturing the collected water samples for Acanthamoeba spp. and examining for the presence of Acanthamoeba trophozoites under the microscope, followed by DNA extraction, DNA amplification and sequencing.

\section{Amoeba cultivation (Non - Nutrient agar seeded with gram-negative bacteria)}

The NN-EI non-nutritive medium (Page Amoeba Saline solution-2.5 mM NaCl, $1 \mathrm{mM} \quad \mathrm{KH}_{2} \mathrm{PO}_{4}, \quad 0.5 \mathrm{mM}$ $\mathrm{Na}_{2} \mathrm{HPO}_{4}, 40 \mathrm{mM} \mathrm{CaCl}$, and $20 \mathrm{mM} \mathrm{MgSO}$ ) seeded with $0.1 \mathrm{ml}$ of a heat inactivated 48-h culture of Escherichia coli BL21 was prepared and the final $\mathrm{pH}$ of the solution adjusted to 6.9. Water in the $50 \mathrm{ml}$ tubes was centrifuged at $1000 \times g$ for $15 \mathrm{~min}$ and the supernatant poured off to expose the pellet which was spread on the already prepared agar plates. The plates were incubated at $30-32{ }^{\circ} \mathrm{C}$ overnight. After one day, the plates were wrapped in polyethene bags and incubated upside down 
at $30-32{ }^{\circ} \mathrm{C}$ up to 7 days. After 3 days of incubation, the plates were monitored for detection of Acanthamoeba trophozoites microscopically daily until the $7^{\text {th }}$ day. The number of Acanthamoeba trophozoites were counted using haemocytometer (MicrobeHunter, Germany) and recorded.

\section{Identification of Acanthamoeba at genus level}

In order to determine the genus of the protozoa, movement and structural properties of amoebae were examined. Distinguishing features of the Acanthamoeba trophozoites were the presence of spiny or fingerlike surface projections called acanthopodia, a prominent contractile vacuole in the cytoplasm and vesicular nucleus with large central nucleolus [11].

\section{Molecular identification of the isolates and phylogenetic analysis \\ Reference strains}

The reference amoeba strain used in this study was the Amplirun ${ }^{\odot}$ Acanthamoeba castellanii DNA Control, $\mathrm{MBC} 054$, and was the positive control for in vitro diagnosis techniques based on nucleic acids amplification (Labconsult, Bruxelles-Brussels, Belgium).

\section{Polymerase chain reaction (PCR) amplification assay for acanthamoebae}

After identifying amoebae from the water samples, genomic DNA was extracted for PCR analysis by chemical lysis and purification of DNA with phenol/chloroform/ isoamyl alcohol extraction method [12]. Five hundred microliters of STE buffer $(0.1 \mathrm{M} \mathrm{NaCl}, 1 \mathrm{mM}$ EDTA, $10 \mathrm{mM}$ Trischloride, PH 8, $1 \%$ SDS) and $10 \mu \mathrm{l}$ proteinase $\mathrm{K}(10 \mathrm{mg} / \mathrm{ml})$ was added directly to each sample in an Eppendorf tube. The samples were incubated at $56{ }^{\circ} \mathrm{C}$ for one hour and then cooled before phenol extraction. An equal volume of phenol-chloroform (521 $\mu \mathrm{l})$ was added to each sample, mixed by vortexing and centrifuged at 13,200 rpm for $10 \mathrm{~min}$. The aqueous layer was recovered and transferred to a new Eppendorf tube. This step was repeated to make two phenol-chloroform extractions. The aqueous layer from each tube was subjected to another chloroform extraction, recovered by centrifugation and transferred to a new Eppendorf tube after which $1000 \mu \mathrm{l}$ of absolute alcohol (96-100\%) was added. The samples were then put in a freezer at $-80{ }^{\circ} \mathrm{C}$ for precipitation overnight. The next day, samples were removed from the freezer and centrifuged at 13,200 rpm for $30 \mathrm{~min}$. After $30 \mathrm{~min}$ the absolute alcohol was poured off. The pellet in each tube was then washed with $1000 \mu \mathrm{l}$ of $70 \%$ alcohol, centrifuged at 13,200 rpm for $15 \mathrm{~min}$ and alcohol poured off to expose the pellet. Finally, the pellet was air dried and dissolved in $50 \mu \mathrm{l}$ of TE buffer.
Amplification of the partial 18S ribosomal RNA (18S rRNA) gene from Acanthamoeba was performed using primers previously shown to be specific for Acanthamoeba spp. [13, 14]. The primer pairs were: forward primer JDP1 (5'GGCCCAGATCGTTTACCGTGAA-3') and reverse primer JDP2 (5'TCTCACAAGCTGCTAGGGAGTCA-3').

Amplification reactions were performed using a DreamTaq PCR kit (Thermoscientific DreamTaq, USA). We used a $25 \mu \mathrm{l}$ reaction volume containing $12.5 \mu \mathrm{l}$ DreamTaq Green PCR Master Mix (2X), $0.5 \mu \mathrm{M}$ forward primer, $0.5 \mu \mathrm{M}$ reverse primer, $9 \mu \mathrm{l}$ nuclease free water and $2.5 \mu \mathrm{l}$ DNA template (50 pg concentration). The PCR was done under the following conditions: Initial denaturation at $94{ }^{\circ} \mathrm{C}$ for $3 \mathrm{~min}$ then 35 cycles with denaturation at $94{ }^{\circ} \mathrm{C}$ for $30 \mathrm{~s}$, annealing at $55{ }^{\circ} \mathrm{C}$ for $30 \mathrm{~s}$, extension at $72{ }^{\circ} \mathrm{C}$ for $30 \mathrm{~s}$ and final extension at $72{ }^{\circ} \mathrm{C}$ for $5 \mathrm{~min}$. A sample of $5 \mu \mathrm{l}$ of each PCR reaction was screened for successful amplification on a $2.5 \%(\mathrm{~W} / \mathrm{V})$ agarose gel stained with ethidium bromide and run against $1 \mathrm{kbp}$ DNA ladder (Finnzymes, Finland). Electrophoresis was performed at $100 \mathrm{~V}$ of current and buffer used was 1X TAE containing $0.5 \mu \mathrm{g} / \mathrm{ml}$ of ethidium bromide. Once enough electrophoretic separation was obtained, the agarose gel was visualised using a UV gel documentation system (Wagtec, UK). The gel images were captured and a soft copy stored.

\section{Nucleic acid sequencing and analysis}

Samples that showed the strongest positive bands (400$600 \mathrm{bp}$ ) were extracted from the gel and the DNA was purified using QIAquick gel extraction kit (Qiagen Inc. Sample and Assay Technologies, Netherlands). The 18S rDNA segment from each of the Acanthamoeba isolates was subjected to cycle sequencing by the dideoxynucleotide chain termination method using the Dyenamic Terminator Cycle sequencing kit with JDP as sequencing primer [14]. The sequencing included $2 \mu \mathrm{l}$ of PCR product, 5XBigDye Buffer, and $2 \mathrm{pmol}$ primer. Sequencing was done in 30 cycles with step 1 at $94{ }^{\circ} \mathrm{C}$ for $30 \mathrm{~s}$, step 2 at $55^{\circ} \mathrm{C}$ for $15 \mathrm{~s}$ and step 3 at $65^{\circ} \mathrm{C}$ for $4 \mathrm{~min}$.

The sequence files were checked for quality and base trimming carried using the Seqbuilder software (Dnastar, USA). For each of the nucleotide query sequences, a search for homologues in the NCBI database was carried out using the blastn tool. Homologues with query coverage $>80 \%$, identity $>70 \%$ and low $\mathrm{E}$ values $(<0)$ were considered. The molecular phylogenetic analysis was then carried out using the Maximum Likelihood Method in MEGA6 [15].

\section{Statistical analysis}

Data was analysed using IBM SPSS version 22. Numerical variables were summarised using mean and standard 
Table 1 Prevalence of Acanthamoeba by water source

\begin{tabular}{llll}
\hline Source & $\begin{array}{l}\text { Acanthamoeba } \\
\text { Number of } \\
\text { samples }\end{array}$ & $\begin{array}{l}\text { Number } \\
\text { positive }\end{array}$ & $\begin{array}{l}\text { Prevalence } \\
(\%)\end{array}$ \\
\hline $\begin{array}{l}\text { Tap Water } \\
\text { Environmental }\end{array}$ & 84 & 36 & 42.9 \\
$\begin{array}{l}\text { Water } \\
\text { Total }\end{array}$ & 324 & 107 & 33 \\
\hline
\end{tabular}

error of the mean (SEM). Univariate analysis to compare the prevalence of Acanthamoeba across sampling sites was done using cross-tabulation with a Chi-square or Fisher's exact test. Variables with a $p$-value of $\leq 0.05$ were taken to be significant. Correlation analysis between environmental variables and Acanthamoeba presence was done using Pearson correlation coefficient ( $\mathrm{r}$ ), a $p$-value of $\leq 0.05$ was considered statistically significant.

\section{Results}

Prevalence of Acanthamoeba per water site source

Acanthamoeba prevalence in environmental and tap water samples was $33 \%$ and $42.9 \%$ respectively (Table 1). The prevalence in various environmental sites where samples were collected was as follows: River Kyambura (39.6 \%), KCB (60.7 \%), FLS (50 \%) and KMC (5.3\%) (Table 2). The results show that the number of organisms isolated was significantly $(p=0.001)$ influenced by the sampling site.

The means (Mean \pm SEM) of the organism in water across sites were as follows from highest to lowest; $\mathrm{KCB}$ (3.44 \pm 0.49$)$, FLS $(3.08 \pm 0.5)$, Tap water $(2.26 \pm 0.4)$, R. Kyambura $(2.23 \pm 0.53)$ and KMC $(0.17 \pm 0.08)$. The highest Acanthamoeba prevalence and means (KCB and FLS) were associated with lower DO (mg/l), higher, Temperature $\left({ }^{\circ} \mathrm{C}\right)$, conductance $(\mu \mathrm{S} / \mathrm{m})$ and TDS (g/l) (Table 2).

\section{Correlation of Acanthamoeba presence and in situ parameters}

Dissolved oxygen (DO) was negatively correlated $(r=$ $-0.231^{\text {sth }}$ ) with Acanthamoeba spp. There was a weak negative correlation $(r=-0.051)$ between water temperature and Acanthamoeba spp. The other parameters (Conductance, pH, TDS and ORP) were positively correlated to the Acanthamoeba spp. (Table 3).

\section{Molecular identification of the isolates and phylogenetic analysis}

Amplicon sizes between 400 and 600 bp were observed (Fig. 1). Six distinct partial Acanthamoeba sequences belonging to the group of sequence types, T1, T2, T4, T5, T6 and T11 were obtained. The sequences were 9899 \% similar; with only two identical to already known Acanthamoeba sequences. Four sequences were not identical to known Acanthamoeba in NCBI. Ultimately, Acanthamoeba spp., Acanthamoeba hatchetti, and Acanthamoeba polyphaga were among the identified, following comparison with the GenBank results from NCBI (Table 4).

\section{Discussion}

Over the past decade, Acanthamoeba has been the most studied FLA due to its ability to cause and exacerbate disease in humans and animal [3]. Disease effects associated with Acanthamoeba often go undetected in Uganda because very little is known about their existence and pathogenic effects, as most communities are completely oblivious of the diseases they might encounter by using contaminated water for cooking, drinking, washing or bathing. The most commonly diagnosed waterborne diseases in Uganda are cholera, campylobacteriosis, shigellosis, salmonellosis and typhoid [16]. Waterborne protozoan parasites Cryptosporidium and Giardia have also been reported but mostly in wild and domestic animals [17], with very scanty literature available on household water systems. There is no information on diseases caused by amoebae in Uganda and yet FLA of the genus Acanthamoeba if present in lethal threshold concentration are highly pathogenic. Acanthamoeba has mostly been associated with granulomatous amoebic encephalitis (GAE), amoebic keratitis (AK), cutaneous lesions and sinusitis in humans [8-10]. Eight species of Acanthamoeba (A. castellanii, A. polyphaga, A. culbertsoni, A. hatchetti, $A$. rhysodes, A. lugdunensis, A. quina and $A$.

Table 2 Presents prevalence, means and in situ parameters per sampling site

\begin{tabular}{|c|c|c|c|c|c|c|c|c|c|c|}
\hline \multirow[b]{3}{*}{ Site } & \multirow[b]{3}{*}{ No. } & \multirow[b]{3}{*}{+ ve } & \multicolumn{2}{|c|}{ Acanthamoeba } & \multirow[b]{2}{*}{$\mathrm{DO}(\mathrm{mg} / \mathrm{l})$} & \multicolumn{2}{|c|}{ In situ parameters } & \multirow[b]{2}{*}{$\mathrm{pH}$} & \multirow[b]{2}{*}{$\operatorname{TDS}(g / l)$} & \multirow[b]{2}{*}{$\mathrm{ORP}(\mathrm{mV})$} \\
\hline & & & & & & $\mathrm{Temp}\left({ }^{\circ} \mathrm{C}\right)$ & Cond $(\mu \mathrm{S} / \mathrm{m})$ & & & \\
\hline & & & Prev (\%) & Mean(土SE) & Mean $( \pm S E)$ & Mean $( \pm S E)$ & Mean $( \pm S E)$ & Mean $( \pm S E)$ & Mean $( \pm S E)$ & Mean $( \pm S E)$ \\
\hline R. Kyambura & 48 & 19 & 39.6 & $2.23 \pm 0.53$ & $4.03 \pm 0.16$ & $21.43 \pm 0.15$ & $150.98 \pm 3.02$ & $7.99 \pm 0.11$ & $113.12 \pm 6.42$ & $-541.9 \pm 52.99$ \\
\hline Kazinga channel bank & 84 & 51 & 60.7 & $3.44 \pm 0.49$ & $1.74 \pm 0.15$ & $25.63 \pm 0.24$ & $273.71 \pm 9.27$ & $9.31 \pm 0.04$ & $182.76 \pm 4.87$ & $-467.8 \pm 29.30$ \\
\hline Fish landing sites & 60 & 30 & 50 & $3.08 \pm 0.53$ & $1.84 \pm 0.21$ & $26.22 \pm 0.34$ & $280.99 \pm 10.36$ & $8.91 \pm 0.12$ & $183.38 \pm 6.84$ & $-412.5 \pm 33.97$ \\
\hline Kazinga mid channel & 132 & 7 & 5.3 & $0.17 \pm 0.08$ & $4.57 \pm 0.26$ & $25.76 \pm 0.20$ & $261.75 \pm 6.78$ & $9.18 \pm 0.07$ & $163.09 \pm 4.04$ & $-454.2 \pm 25.09$ \\
\hline Tap water & 84 & 36 & 42.9 & $2.26 \pm 0.4$ & $4.08 \pm 0.27$ & $26.89 \pm 0.36$ & $163.26 \pm 111.69$ & $7.73 \pm 0.10$ & $108.94 \pm 7.50$ & $-322.8 \pm 23.25$ \\
\hline
\end{tabular}


Table 3 Correlation coefficient $(r)$ between environmental variables and Acanthamoeba presence

\begin{tabular}{lll}
\hline In situ parameter & Correlation coefficient $(r)$ & Significance \\
\hline $\mathrm{DO}(\mathrm{mg} / \mathrm{ML})$ & $-.231^{* *}$ & 0.001 \\
Temp $\left({ }^{\circ} \mathrm{C}\right)$ & -.051 & 0.3 \\
$\mathrm{Cond}(\mu \mathrm{S} / \mathrm{m})$ & .090 & 0.07 \\
$\mathrm{pH}$ & 0.5 & 0.31 \\
$\mathrm{TDS}(\mathrm{g} / \mathrm{L})$ & 0.09 & 0.09 \\
$\mathrm{ORP}(\mathrm{mV})$ & 0.2 & 0.059 \\
\hline
\end{tabular}

**very significant

griffini) have been previously documented by researchers as aetiologic agents in Acanthamoeba keratitis [18] which is common in individuals using dirty contact lenses as well as those washing and bathing with contaminated water [3]. The effects of Acanthamoeba infection has been found to be more severe in HIV/AIDS patients and other immunocompromised individuals $[8,9]$.

The present study investigated the prevalence and molecular genotyping of Acanthamoeba in environmental water bodies and communal piped tap water systems in Queen Elizabeth Protected Area, Western Uganda. Acanthamoeba prevalence in environmental water was $33 \%$ and in tap water $42.9 \%$. The low prevalence in environmental samples could be due to a larger number of samples (324) compared to the smaller number of tap water samples (84) collected. The higher prevalence in tap water could also be due to the formation of bacterial biofilms along the water pipes and tap outlet that attracts more predatory Acanthamoeba spp. Acanthamoeba and bacteria are constantly involved in a predator-prey relationship, with Acanthamoeba engulfing and feeding on numerous bacterial colonies [3, 9, 19]. These findings are in agreement with previous studies that detected $51 \%$ and $34 \%$ prevalence in household tap water, all higher than the prevalence in environmental water [20,21]. Previous studies have also indicated that the prevalence of Acanthamoeba in environmental and domestic water can vary from as low as $1 \%$ to as high as $79 \%[12,19,22-25]$, all depending on sample size and site.
Taking into consideration the prevalence from a specific environmental sample sources (R. Kyambura (39.6\%), KCB (60.7 \%), FLS (50 \%) and KMC (5.3 \%), it is evident that water from the mid-channel had the least prevalence of the organisms; probably because this water was clearer and less contaminated with organic matter compared to that from other sites. The present study reports high microbial loads of Acanthamoeba at KCB (3.44 \pm 0.49$)$ and R. Kyambura $(3.08 \pm 0.53)$. These same sampling areas were associated with lower levels of DO (mg/l), elevated Temperature $\left({ }^{\circ} \mathrm{C}\right)$ and conductance $(\mu \mathrm{S} / \mathrm{m})$ and TDS $(\mathrm{g} / \mathrm{l})$ (Table 2) compared to other sites. We report a significant correlation of Acanthamoeba with mean dissolved oxygen $\left(r=-.231^{* * *}\right)$ and temperature $(r=-.051)$. The high prevalence and mean of the organisms at the banks and FLS could be due to contamination of the water by formation of more organic matter from rotting leaves, household refuse and faecal matter dumped by communities living nearby. This increases the build-up of bacteria, consequently increasing the number of Acanthamoeba spp. and other amoebae. This concurs with previous findings, that there are more amoebae when there is a build-up of more organic matter in soil and water because the organic fraction contains organic molecules needed for microbial development [26-28]. Acanthamoeba spp. are common pathogenic FLA whose distribution is variable and often but not always influenced by physico-chemical parameters [29]. Acanthamoeba spp. have been found to be more prevalent in contaminated, bacteria-rich water [29] irrespective of the physico-chemical parameters of the water. However, very high and very low temperature, as well as dissolved oxygen will ultimately lead to low Acanthamoeba trophozoite counts. Acanthamoeba spp. being ubiquitous, exist in many natural environments and domestic water systems but their numbers fluctuate to a certain extent with precipitating factors like dissolved oxygen, temperature, organic matter, conductivity, oxidation reduction potential, although not so significantly [29].

Classifying the genus Acanthamoeba remains a debatable topic but the molecular genotyping being used currently has proved precise in isolate identification, producing more

\begin{tabular}{|l|l|llllll}
\hline M & 1 & 2 & 3 & 4 & 5 & 6 & A
\end{tabular}


Table 4 Acanthamoeba T-genotype groups isolated in this study and associated diseases

\begin{tabular}{|c|c|c|}
\hline T-genotype & Species Name & Associated human disease \\
\hline$\overline{\mathrm{T} 1}$ & Acanthamoeba spp. ${ }^{a}$ & Encephalitis $[8,9]$ \\
\hline $\mathrm{T} 2$ & Acanthamoeba spp. ${ }^{a}$, A. palestinensis, A. pustulosa & Keratitis and sinusitis $[8,10]$ \\
\hline T3 & A. griffini, A. pearcei, Acanthamoeba spp. ${ }^{a}$, & Keratitis [8] \\
\hline T4 & A. castellanii, A. polyphaga ${ }^{a}$, A. lugdunensis, A. rhysodes, A. divionensis, A. mauritaniensis & Keratitis $[8,18]$ \\
\hline T5 & Acanthamoeba spp ${ }^{\mathrm{a}}$, A. lenticulata & Keratitis [8] \\
\hline T6 & Acanthamoeba hatchetti ${ }^{a}$, A. palestinensis & Keratitis [8] \\
\hline $\mathrm{T7}$ & A. astronyxis & Unknown \\
\hline T8 & A. tubiashi & Unknown \\
\hline T9 & A. healyi & Unknown \\
\hline $\mathrm{T} 10$ & A. culbertsoni & Keratitis and encephalitis $[8,9$ \\
\hline $\mathrm{T} 11$ & Acanthamoeba hatchettia ${ }^{\mathrm{a}}$ A. stevensoni, A.quina & Keratitis and encephalitis [9] \\
\hline $\mathrm{T} 12$ & A. healyi & Encephalitis $[8,9]$ \\
\hline T13 & Acanthamoeba spp. & Unknown \\
\hline $\mathrm{T} 14$ & Acanthamoeba spp. & Unknown \\
\hline $\mathrm{T} 15$ & A. jacobsi & Keratitis [8] \\
\hline T16 & Acanthamoeba spp. & Unknown \\
\hline T17 & Acanthamoeba spp. & Unknown \\
\hline $\mathrm{T} 18$ & Acanthamoeba spp. & Unknown \\
\hline
\end{tabular}

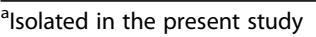

than 25 species. Acanthamoeba sequence types have been previously grouped from $\mathrm{T} 1$ to $\mathrm{T} 18$. In the present study six distinct partial Acanthamoeba sequences belonging to sequence T-genotype groups $\mathrm{T} 1, \mathrm{~T} 2, \mathrm{~T} 4, \mathrm{~T} 5, \mathrm{~T} 6$ and $\mathrm{T} 11$, with only two identical (Acanthamoeba hatchetti and Acanthamoeba polyphaga) to already known Acanthamoeba spp. sequences from NCBI comparisons were obtained. The remaining four Acanthamoeba spp. which were not classified to species level may be unique to Uganda. Two isolates belonged to T4, whereas T1, T2, T5, T6 and T11 had only one isolate each. The Acanthamoeba strain identified as genotype T4 and T6 was isolated from both environmental and tap water samples. All the other strains were from environmental samples. Previous studies indicate that T2 and T6 are largely environmental isolates that are phylogenetically close to one another [30] although they have also been both isolated from clinical AK cases [31]. Acanthamoeba T3 and T11 are closely related to T4 and have been found to also be responsible for AK [32]. Acanthamoeba of $\mathrm{T} 4$ is reported as the most commonly encountered and most diverse T-genotype group found in both environmental and clinical samples. [30]. Genotype $\mathrm{T} 5$ is the second most prevalent [12], mainly isolated from sewage dump locations and AK infections [30].

The findings from the present study indicate that there is a high likelihood of contamination of both environmental and domestic tap water systems with Acanthamoeba spp. indicating poor water source quality and possible predisposition of the end users to a variety of infections. Since there are no previous studies on Acanthamoeba or any other amoeba in Uganda, it is hard to know the current situation in terms of the effect on human health but we can state that the various genotypes isolated from water samples in the present study could be responsible for silent illnesses that often lead to severe morbidities and mortalities among communities. Acanthamoeba genotypes T1 (responsible for encephalitis), T2 (keratitis and sinusitis), T3/T5 (keratitis) and T11 (keratitis and encephalitis) isolated from the water samples pose a high risk to the households in QEPA using both environmental and piped tap water. It is, therefore, imperative that more research on Acanthamoeba spp. and other amoebae is done in Uganda to build up knowledge of the types, prevalence, diagnosis, prevention and treatment measures.

\section{Conclusion}

There was a high prevalence of Acanthamoeba in communal piped tap and environmental water used by communities (at fish landing sites, channel and river banks). Increasing prevalence of Acanthamoeba in water means that there is increased density of prey organisms (bacteria). This can be an indicator of poor environmental and domestic tap water quality.

\section{Abbreviations}

+ve: positive; C: celsius; AK: amoebic keratitis; CNS: central nervous system; FLA: free living amoeba; FLS: fish landing site; g: gravitational force; g: grams; HIV/AIDS: Human Immunodeficiency Virus/Acquired Immune Deficiency Syndrome; KCB: Kazinga channel bank; KMC: Kazinga mid channel; I: liter; 
mg: milligrams; ml: milliliters; mM: millimolar; mV: millivolts; NCBI: National Center for Biotechnology Information; No.: number; pg: picogram; pmol: picomoles; Prev: prevalence; QEPA: Queen Elizabeth Protected Area; rpm: revolutions per minute; $\mathrm{V}$ : volts; $\mu \mathrm{S}$ : microseconds.

\section{Competing interests}

The authors declare that they have no competing interests.

\section{Authors' contributions}

CS carried out all the field data collection, carried out the culturing and DNA extraction and drafted the manuscript. JE, MO and IN supervised the data collection, laboratory work and the development of the manuscript. PKM and SO carried out organism cultures and molecular diagnostic studies. BGN developed the field study designs. JM participated in sequence alignment and drafting of the manuscript. CKD carried out the statistical analysis. All authors read and approved the final version of the manuscript.

\section{Authors' information}

Dr Celsus Sente: Wildlife Veterinarian, Assistant Lecture \& Ph.D. student, with special interest in public health, water-borne diseases and water microbial genomics.

Professor Michael Ocaido: Epidemiologist and Chair, Department of Wildlife and Aquatic Animal Resources (WAAR).

Assoc. Prof. Joseph Erume: Senior Lecturer, Department Biomolecular Resources. Dr Irene Naigaga: Lecturer, Department WAAR.

Mr Sylvester Ochwo: Senior Laboratory technologist and manager, Molecular Biology Laboratory (MOBILA)

Mr Phillip K Magambo: Ph.D. student and Senior Laboratory technologist, MOBILA. Dr Julius Mulindwa: Lecturer, Department of Biochemistry and Sports Science. Dr Benigna G Namara: Medical Doctor, Uganda Virus Research Institute (UVRI). Dr Charles Kato Drago: Lecturer, Department of Biomolecular Resources. Mr George Sebyatika: Laboratory assistant, MOBILA. Mr Kevin Muwonge: Laboratory Assistant, MOBILA.

\section{Acknowledgements}

We would like to thank WaterNet, SIG-RISE and CARNEGIE-Next Generation of African Academics (NGAA-Carnegie) for funding this research, and Molecular Biology Laboratory (MOBILA), Makerere University for providing space for carrying out the study.

\section{Author details}

'Department of Wildlife and Aquatic Animal Resources (WAAR), School of Veterinary Medicine and Animal Resources (SVAR), College of Veterinary Medicine, Animal Resources and Biosecurity (COVAB), Makerere University, P.O. Box 7062, Kampala, Uganda. ${ }^{2}$ Department of Biomolecular Resources and Biolab Sciences, School of Biosecurity, Biotechnical and Laboratory Sciences (SBLS), College of Veterinary Medicine, Animal Resources and Biosecurity (COVAB), Makerere University, P.O. Box 7062, Kampala, Uganda. ${ }^{3}$ Medical Research Council (MRC)/Uganda Virus Research Institute (UVRI), Research Unit on AIDS, P.O. Box 49, Entebbe, Uganda. ${ }^{4}$ Department of Biochemistry and Sports Science, College of Natural Sciences (CONAS), Kampala, Uganda.

\section{Received: 20 August 2015 Accepted: 24 February 2016} Published online: 03 March 2016

\section{References}

1. Obi CL, Potgieter N, Bessong PO, Matsaung G. Scope of potential bacterial agents of diarrhoea and microbial assessment of quality of river water sources in rural Venda communities in South Africa. Water Sci Technol. 2003;47(3):59-64.

2. Zamxaka A, Pironcheva G, Muyima G. Bacterial community patterns of domestic water sources in the Gogogo and Nkonkobe areas of the Eastern Cape Province, South Africa. Water SA. 2004;30(3):341-6.

3. Khan NA. Acanthamoeba: biology and increasing importance in human health. FEMS Microbiol Rev. 2006:30(4):564-95.

4. Khan N. Acanthamoeba: Biology and Pathogenesis. University of Nottingham: Caister Academic Press; 2009.

5. Costa AO, Castro EA, Ferreira GA, Furst C, Crozeta MA, Thomaz-Soccol V. Characterization of acanthamoeba isolates from dust of a public hospital in Curitiba, Parana, Brazil. J Eukaryot Microbiol. 2010;57(1):70-5.
6. Schuster FL, Visvesvara GS. Free-living amoebae as opportunistic and nonopportunistic pathogens of humans and animals. Int J Parasitol. 2004;34(9): 1001-27.

7. Dey R, Hoffman PS, Glomski IJ. Germination and amplification of anthrax spores by soil-dwelling amoebas. Appl Environ Microbiol. 2012;78(22):8075-81.

8. Dunand VA, Hammer SM, Rossi R, Poulin M, Albrecht MA, Doweiko JP, et al. Parasitic sinusitis and otitis in patients infected with human immunodeficiency virus: report of five cases and review. Clin Infect Dis. 1997;25(2):267-72

9. Amir S. Acanthamoeba castellanii as a Host and Model to Study Bacterial Virulence. Solna: Karolinska Universitetssjukhuset Huddinge; 2009.

10. Torno Jr MS, Babapour R, Gurevitch A, Witt MD. Cutaneous acanthamoebiasis in AIDS. J Am Acad Dermatol. 2000:42(2 Pt 2):351-4.

11. Smirnov AV, Goodkov AV. An illustrated list of basic morphotypes of Gymnamoebia (Rhizopoda, Lobosea). Paraitology. 1999;11:20-9.

12. Pelandakis $M$, Pernin $P$. Use of multiplex $P C R$ and $P C R$ restriction enzyme analysis for detection and exploration of the variability in the free-living amoeba Naegleria in the environment. Appl Environ Microbiol. 2002;68(4): 2061-5.

13. Schroeder JM, Booton GC, Hay J, Niszl IA, Seal DV, Markus MB, Fuerst PA, Byers TJ. Use of subgenic $18 \mathrm{~S}$ ribosomal DNA PCR and sequencing for genus and genotype identification of acanthamoebae from humans with keratitis and from sewage sludge. J Clin Microbiol. 2001;39(5):1903-11.

14. Booton GC, Kelly DJ, Chu YW, Seal DV, Houang E, Lam DS, Byers TJ, Fuerst PA. 185 ribosomal DNA typing and tracking of Acanthamoeba species isolates from corneal scrape specimens, contact lenses, lens cases, and home water supplies of Acanthamoeba keratitis patients in Hong Kong. J Clin Microbiol. 2002:40(5):1621-5.

15. Tamura K, Stecher G, Peterson D, Filipski A, Kumar S. MEGA6: molecular evolutionary genetics analysis version 6.0. Mol Biol Evol. 2013;30(12):2725-9.

16. Ojore G. Uganda: 2,000 Children Die of Diarrhoea in Africa Daily-WaterAid. In: New Vision. Uganda: New Vision Publishing; 2012.

17. Salzer JS, Rwego IB, Goldberg TL, Kuhlenschmidt MS, Gillespie TR. Giardia sp. and Cryptosporidium sp. infections in primates in fragmented and undisturbed forest in western Uganda. J Parasitol. 2007;93(2):439-40.

18. CDC: Acanthamoeba keratitis associated with contact lenses. In: MMWR Morb Mortal Wkly Rep vol. 35. United States. 1986: 405-408.

19. Bagheri H, Shafiei R, Shafiei F, Sajjadi S. Isolation of Acanthamoeba spp. from drinking waters in several hospitals of iran. Iran J Parasitol. 2010; 5(2):19-25.

20. Stockman LJ, Wright CJ, Visvesvara GS, Fields BS, Beach MJ. Prevalence of Acanthamoeba spp. and other free-living amoebae in household water Ohio, USA-1990-1992. Parasitol Res. 2011;108(3):621-7.

21. Ghadar-ghadr S, Solhjoo K, Norouz-nejad M, Rohi R, Zia-Jahromi S. Isolation and identification of free living amoeba (Naegleria and Acanthamoeba) in Shiraz water resources by morphological criteria. Pars Jahrom Univ Med Sci. 2012:10(3):33-42

22. Marciano-Cabral F, Puffenbarger R, Cabral GA. The increasing importance of Acanthamoeba infections. J Eukaryot Microbiol. 2000:47(1):29-36.

23. Shoff ME, Rogerson A, Kessler K, Schatz S, Seal DV. Prevalence of Acanthamoeba and other naked amoebae in South Florida domestic water. J Water Health. 2008;6(1):99-104.

24. Kao PM, Hsu BM, Chen CT, Huang SW, Kao ES, Chen JL, Wu NM, Ji WT. Identification and quantification of the Acanthamoeba species and genotypes from reservoirs in Taiwan by molecular techniques. Acta Trop. 2014;132:45-50

25. Kiss C, Barna Z, Vargha M, Torok JK. Incidence and molecular diversity of Acanthamoeba species isolated from public baths in Hungary. Parasitol Res. 2014;113(7):2551-7.

26. Alexander M. Introduction to Soil Microbiology. 2nd ed. Mishawaka: Krieger Pub Co; 1977

27. Rodriguez-Zaragoza S, Mayzlish E, Steinberger $Y$. Vertical distribution of the free-living amoeba population in soil under desert shrubs in the Negev desert, Israel. Appl Environ Microbiol. 2005:71(4):2053-60.

28. Pruden M, Falkinham J, Williams K, Wang H, Martins K, Rhoads W: Relationship Between Biodegradable Organic Matter and Pathogen Concentrations in Premise Plumbing. Water Research Foundation; 2013 58-90.

29. Bonilla-Lemus P, Caballero Villegas AS, Carmona Jiménez J, Lugo Vázquez A. Occurrence of free-living amoebae in streams of the Mexico Basin. Exp Parasitol. 2014;145(Supplement):S28-33. 
30. Crary M. Genetic Variability and its Relationship to Acanthamoeba Pathogenesis. In: Molecular Genetics. Columbus: Ohio State University; 2012.

31. Maghsood AH, Sissons J, Rezaian M, Nolder D, Warhurst D, Khan NA. Acanthamoeba genotype T4 from the UK and Iran and isolation of the T2 genotype from clinical isolates. J Med Microbiol. 2005;54(Pt 8):755-9.

32. Ledee DR, Hay J, Byers TJ, Seal DV, Kirkness CM. Acanthamoeba griffini. Molecular characterization of a new corneal pathogen. Invest Ophthalmol Vis Sci. 1996;37(4):544-50

Submit your next manuscript to BioMed Central and we will help you at every step:

- We accept pre-submission inquiries

- Our selector tool helps you to find the most relevant journal

- We provide round the clock customer support

- Convenient online submission

- Thorough peer review

- Inclusion in PubMed and all major indexing services

- Maximum visibility for your research

Submit your manuscript at www.biomedcentral.com/submit 